\title{
Crotoxin enhances the antitumor activity of gefinitib (Iressa) in SK-MES-1 human lung squamous carcinoma cells
}

\author{
JUN-HUA WANG ${ }^{1}$, YAN XIE ${ }^{1}$, JUN-CHAO WU $^{2}$, RONG HAN $^{2}$, \\ PAUL F. REID ${ }^{3}$, ZHENG-HONG QIN ${ }^{2}$ and JING-KANG HE ${ }^{1}$ \\ ${ }^{1}$ Department of Cardiothoracic Surgery, The First Affiliated Hospital of Soochow University, Suzhou 215006; \\ ${ }^{2}$ Department of Pharmacology and Laboratory of Aging and Nervous Diseases, School of Pharmaceutical \\ Science, Soochow University, Suzhou 215123, P.R. China; ${ }^{3}$ Celtic Biotech, Ltd., Dublin, Ireland
}

Received November 9, 2011; Accepted January 16, 2012

DOI: $10.3892 /$ or.2012.1677

\begin{abstract}
Crotoxin (CrTX), a neurotoxin, is isolated from the venom of South American rattlesnakes and has potent antitumor activity. Here, we investigated the antitumor effect of CrTX on the SK-MES-1 human lung squamous cell carcinoma cell line that has acquired resistance to epidermal growth factor receptor tyrosine kinase inhibitors. CrTX caused G1 arrest and p-JNK protein upregulation that resulted in apoptosis of SK-MES-1 cells. SP600125, a specific inhibitor of p-JNK, could rescue SK-MES-1 cells from CrTX-induced apoptosis. CrTX and gefinitib (Iressa) both inhibited the viability and proliferation of SK-MES-1 cells in a dose- and time-dependent manner. The combination of CrTX and Iressa significantly enhanced the antitumor activity of Iressa. In vivo studies revealed that CrTX caused increased damage to blood vessels and reduced tumor size when combined with Iressa. The present study showed that the JNK signal transduction pathway mediated the anti-apoptotic effect of CrTX, and furthermore, CrTX could enhance the antitumor effect of tyrosine kinase inhibitors in cells with acquired resistance.
\end{abstract}

\section{Introduction}

According to the US Centers for Disease Control and Prevention, the number of deaths from lung cancer is higher than any other type of cancer, which holds true for both men and women (1). Its overall 5-year survival rate is only $8-14 \%$ following diagnosis and $40 \%$ after complete surgical resection. NSCLC represents $\sim 80 \%$ of the total lung cancer cases, and the subtypes include adenocarcinoma, squamous carcinoma, and large cell carcinoma (2). The squamous carcinoma subtype

Correspondence to: Dr Jing-Kang He, Department of Cardiothoracic Surgery, The First Affiliated Hospital of Soochow University, Suzhou 215006, P.R. China

E-mail: jkhe001@163.com

Key words: crotoxin, gefinitib, EGFR tyrosine kinase inhibitors, antitumor, JNK pathway accounts for $\sim 50 \%$ of lung cancers. Although tyrosine kinase inhibitors have proven useful in combination with chemotherapy against lung cancer, they have demonstrated good efficacy only in $10-15 \%$ of lung cancers that possess a sensitizing mutation in the epidermal growth factor receptor (3). Crotoxin (CrTX), the dominant toxin of the South American rattlesnake (Crotalus durissus terrificus) venom (4), was the first snake venom protein to be purified and crystallized. It is a non-covalent complex formed by two non-identical subunits, one acidic (subunit A/crotapotin) and one basic (subunit B/ crotactine). Subunit B is a phospholipase A2 (PLA2) formed by a single chain of 122 amino acid residues cross-linked by seven disulfide bonds (5). The classic biological activities normally attributed to CrTX include neurotoxicity, myotoxicity, and nephrotoxicity. Many studies recently have shown that CrTX also has immunomodulatory, anti-inflammatory, antimicrobial and analgesic actions. Studies have also reported that CrTX has antitumor effects (6). However, the pathway to programmed cell death remains to be clearly determined and may be tumor-dependent $(7,8)$. Interestingly, CrTX appears to have cytocidal activity that correlates directly with tumors that express higher levels of the epidermal growth factor receptor (EGFR) though CrTX stimulated tyrosine phosphorylation of the EGFR; the significance of this observation has yet to be established (9).

Our previous studies revealed that the cytocidal mechanism of action of CrTX may be more complex than previously thought. We have demonstrated that apoptosis and autophagy are activated during CrTX-induced death of cancer cells. These studies included K562 leukemia cells that have resistance to imatinib due to a constitutive tyrosine kinase activity (7). This study was undertaken to evaluate the anti-lung cancer efficacy of CrTX in combination with Iressa and to further establish the molecular mechanisms by which CrTX exerts its antitumor functions by looking at the expression of the pro-apoptotic proteins, caspase-3 and p-JNK, and the apoptosis inhibitor protein, Bcl-2.

\section{Materials and methods}

Drug preparation. Crotoxin was supplied by Celtic Biotech Ltd. (Dublin, Ireland). It was purified from Crotalus durissus 
terrificus venom by a combination of size exclusion and anion exchange (4). The identity of the protein was confirmed through molecular weight determination by mass spectrometry (showing averaged signals at 9500 and 14500, in addition to the presence of isoforms). Purity was determined by PAGE and size exclusion $>99 \%$. Lethality in mice was determined by the i.p. injection of $0.1 \mathrm{mg}$ with death being recorded within $3 \mathrm{~h}$.

Cell culture and drug treatment. SK-MES-1 cells, a human lung squamous carcinoma cell line with acquired resistance to epidermal growth factor receptors and tyrosine kinase inhibitors, were purchased from the Shanghai Institute of Cell Biology. Cells were cultured in RPMI-1640 medium (Gibco, Rockville, MD, USA) containing $10 \%$ heat-inactivated fetal bovine serum (Gibco), 0.03\% L-glutamine (Sigma, St. Louis, MO, USA) and $200 \mathrm{U} / 1$ insulin, and incubated in a $5 \% \mathrm{CO}_{2}$ atmosphere at $37^{\circ} \mathrm{C}$. Cells in mid-log phase were used in all the experiments. To determine the dose- and time-response of SK-MES-1 cells to CrTX, SK-MES-1 cells were plated into 96-well microplates ( $10^{4}$ cells/well) and cultured for $24 \mathrm{~h}$. CrTX $(12.5,25,50$ or $100 \mu \mathrm{g} / \mathrm{ml})$, Iressa $(1.25,2.5,5$ or $10 \mu \mathrm{mol} / \mathrm{l})$, Iressa $2.5 \mu \mathrm{mol} / 1$ with CrTX $(12.5,25,50$ and $100 \mu \mathrm{g} / \mathrm{ml})$ or CrTX $25 \mu \mathrm{g} / \mathrm{ml}$ with Iressa $(1.25,2.5,5$ or $10 \mu \mathrm{mol} / \mathrm{l})$ were added to the culture medium, respectively.

Antibodies against phosphorylated c-Jun N-terminal kinase (p-JNK), Bcl-2 and cleaved caspase-3 were purchased from Cell Signaling Technology (Woburn, MA, USA). SP600125, a specific inhibitor of p-JNK, was purchased from Sigma.

Cell viability assay. Cell viability was assessed with a 3-(4,5-dimethylthiazol-2-yl)-2,5-diphenyltetrazolium bromide reduction assay (MTT) (Sigma) 24, 48 and $72 \mathrm{~h}$ after drug treatment as previously described (10). The MTT solution was added to the culture medium $(500 \mu \mathrm{g} / \mathrm{ml}) 4 \mathrm{~h}$ before the end of treatment and the reaction was terminated by the addition of DMSO. After incubation at room temperature for $30 \mathrm{~min}$ and gentle agitation for $10 \mathrm{~min}$, the absorbance value (A) at $570 \mathrm{~nm}$ was read using the Benchmark Microplate Reader (Bio-Rad Laboratories, Hercules, CA, USA). Three independent experiments were performed to generate an average value as the final result for analysis. The percentage of cell death was calculated as following: cell death $(\%)=\left(1-\mathrm{A}_{\text {experiment well }} / \mathrm{A}_{\text {positive control well }}\right)$ $\mathrm{x} 100$.

Cell colony formation assay. The capability of cell colony formation corresponded to the degree of malignancy of the tumor. The more cell colonies formed, the more malignant the tumor was (11). Cells in mid-log phase were digested into a single cell suspension and inoculated into 24-well plates. Each well was inoculated with 200 cells. After $24 \mathrm{~h}$, when the cells adhered to the plate, the medium was removed and various concentrations of CrTX in the medium were applied to treat the cells for $72 \mathrm{~h}$. Subsequently, the medium was changed to fresh RPMI-1640 medium and the cells were incubated for 12 days. Then, cells were fixed with methanol and stained with Giemsa. The colonies including $>50$ cells were calculated. The experiments were repeated three times independently.

Cell cycle analysis. Flow cytometry (FCM) is usually used to determine cell cycle progress and apoptosis $(12,13)$. Five experimental groups were included in the analysis: control; CrTX $(25 \mu \mathrm{g} / \mathrm{ml}) ;$ SP600125 $(10 \mu \mathrm{mol} / \mathrm{l})$ with CrTX $(25 \mu \mathrm{g} / \mathrm{ml})$; Iressa $(5 \mu \mathrm{mol} / \mathrm{l})$; and CrTX $(25 \mu \mathrm{g} / \mathrm{ml})$ with Iressa $(5 \mu \mathrm{mol} / \mathrm{l})$. SP600125 was added to the culture medium $1 \mathrm{~h}$ before CrTX. After being treated for $24 \mathrm{~h}$, cells were harvested using $0.25 \%$ trypsin, and $10^{6}$ cells/sample were aliquoted for analysis. To avoid membrane damage as much as possible, cells were observed with the inverted microscopy after about 2 min of trypsin digestion, and then removed from the flask when the shapes of most cells changed from long spindle-shaped to round. The cells were centrifuged at 5,000 $\mathrm{x}$ g at $4^{\circ} \mathrm{C}$ for $5 \mathrm{~min}$ and washed in cooled PBS, fixed with pre-cooled $70 \%$ ethanol for $24 \mathrm{~h}$, and treated with $200 \mu \mathrm{l}$ RNase A (1 g/l) for $30 \mathrm{~min}$. Propidium iodide (PI) was added to a final concentration of $20 \mu \mathrm{g} / \mathrm{ml}$ for $30 \mathrm{~min}$ in the dark. Finally, the cell cycle was analyzed with FCM (14).

Detection of apoptosis by Annexin-V staining. Cell treatments were the same as previously described. The cells were harvested after treatment, washed twice with pre-chilled PBS $\left(4^{\circ} \mathrm{C}\right)$, and resuspended in $500 \mu \mathrm{l}$ binding buffer to a final cell concentration of $1-5 \times 10^{5}$ cells $/ \mathrm{ml}$. They were incubated in the dark with $5 \mu \mathrm{l}$ Annexin-V and $5 \mu \mathrm{l}$ PI solution of $20 \mu \mathrm{g} / \mathrm{ml}$ for $30 \mathrm{~min}$. Subsequently, the suspension was analyzed by FCM.

Protein preparation and immunoblotting. Cells were harvested and rinsed with ice-cooled PBS twice. Five volumes of western blot lysing buffer for each volume of cell pellets was added and the mixture was sonicated on ice $(1 \mathrm{sec} / \mathrm{ml}$ per sonicate, resting $30 \mathrm{sec}$ between intervals, for a total of 5 times). Microcentrifugation was performed at $10,600 \times \mathrm{g}$ at $4^{\circ} \mathrm{C}$ for $10 \mathrm{~min}$ and the supernatant was preserved at $-70^{\circ} \mathrm{C}$ for later use. The protein concentration was determined using the BCA kit (\#23225, Pierce, Rockford, IL, USA). Proteins were separated with $10 \%$ SDS-PAGE gel, transferred to nitrocellulose membrane and immunoblotted with antibodies against Bcl-2 (1:500, sc-7382, Santa Cruz Biotechnology, Santa Cruz, CA, USA), p-JNK (1:1000, \#4668, Cell Signaling Technology), or caspase-3 (1:500, \#9662, Cell Signaling Technology) at $4^{\circ} \mathrm{C}$ overnight. The reaction of primary antibodies was detected with horseradish peroxidase-conjugated secondary antibodies used at a 1:5000 dilution in blocking solution for $1 \mathrm{~h}$ at room temperature. Immunoreactivity was detected by enhance chemiluminescence (SuperSignal West Pico Chemiluminescent Substrate (\#34077, Pierce) and visualized by autoradiography. Protein $\beta$-actin (1:5000, \#A5441, Sigma) was used as a loading control.

Xenotransplantation and drug treatment. All animals used in this study were handled strictly according to the guidelines for use and care of experimental animals approved by the Ethics Committee of Soochow University. Twenty-six female Balb/c nude mice with an average body weight of 18-20 g (aged 4-6 weeks) were housed in an specific pathogen free animal facility. All manipulations (i.e. handling, invasive procedures and tumor volume measurements) were performed in a laminar flow hood under strict sterile conditions. Mice were injected with $10^{7}$ cells $/ \mathrm{ml}$ suspended in $0.2 \mathrm{ml}$ PBS into the left axillary space tissue. Mice were monitored daily until detection of the first tumor nodule. Tumor nodules were first noted in eight of the 20 mice $(40 \%)$ at 3 days after xenotransplantation. 
A

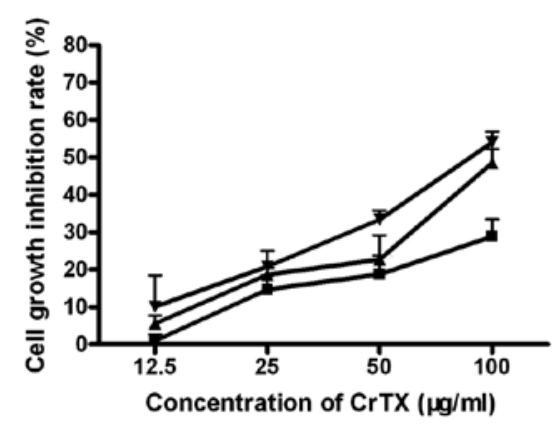

C

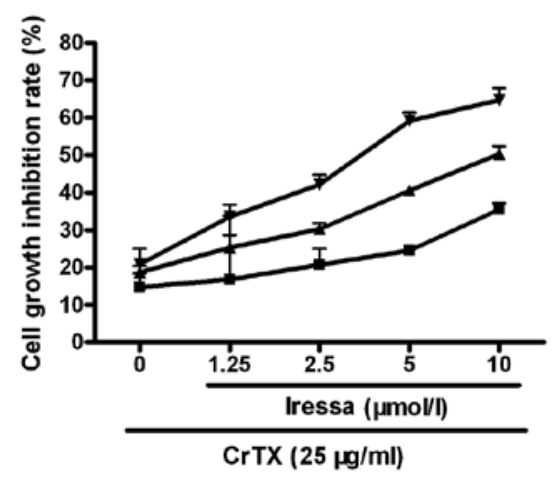

B

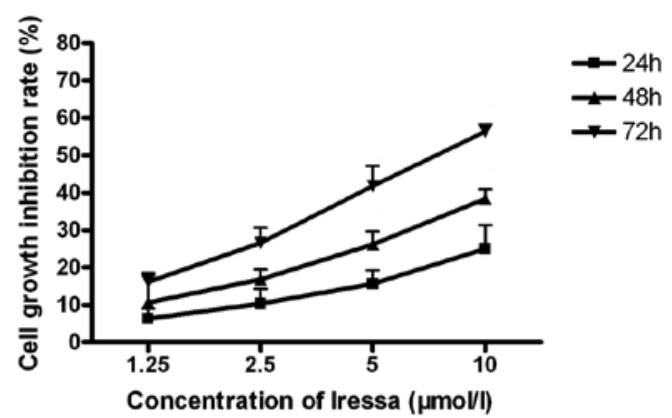

D

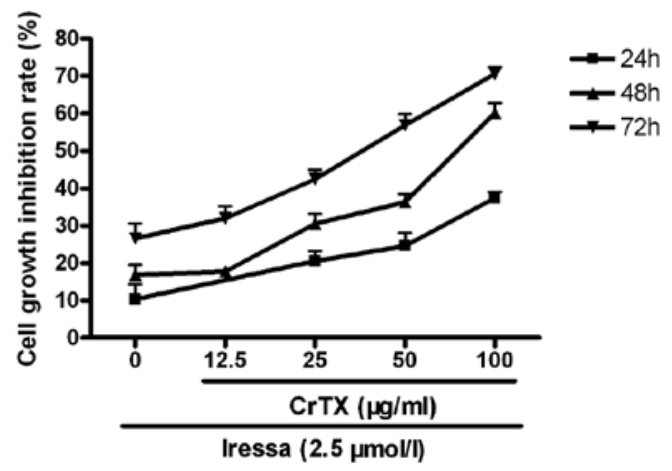

Figure 1. Effects of CrTX and Iressa on the viability of SK-MES-1 cells. Cell viability was assessed by MTT 24,48 and $72 \mathrm{~h}$ after drug treatment as described in the text. After the MTT standard procedure, the absorbance value, A, at $570 \mathrm{~nm}$ was recorded. (A and B) The effect of CrTX and Iressa on cell growth individually; (C and D) the effect of the combination of CrTX and Iressa on cell growth. The percentage of cell death was calculated as followings: cell death $(\%)=\left(1-A_{\text {experiment well }} / A_{\text {positive control well }}\right) \times 100 ; n=3$. Mean \pm SD.

Treatment with CrTX was initiated 11 days after xenotransplantation when the tumor reached 5-6 $\mathrm{mm}$ in diameter. Except for 2 no-tumor mice, 24 mice were randomly assigned to one of four experimental groups ( $\mathrm{n}=6$ per group): control; CrTX (10 $\mu \mathrm{g} / \mathrm{kg}$, i.p., twice weekly); Iressa $(100 \mathrm{mg} / \mathrm{kg} / \mathrm{day}$, i.g., daily); and CrTX with Iressa (CrTX $10 \mu \mathrm{g} / \mathrm{kg}$, i.p., twice weekly with Iressa $100 \mathrm{mg} / \mathrm{kg} /$ day, i.g., daily). At the end of 30 days treatment, the mice were sacrificed, and the tumor xenografts were removed, sectioned and analyzed with transmission electron microscopy (TEM).

Statistical analysis. For statistical analysis, all data were presented as mean \pm SEM. Statistical analysis was carried out by ANOVA followed by the Dunnett's t-test, considering $\mathrm{P}<0.05$ to denote significant differences.

\section{Results}

CrTX potentiates antitumor effects of Iressa. Both CrTX and Iressa inhibited SK-MES-1 cell viability in a time- and dosedependent manner. The MTT assay revealed that after $24 \mathrm{~h}$ of treatment, the inhibitory rates of CrTX $(4 \mu \mathrm{mol} / 1)$ and Iressa $(10 \mu \mathrm{mol} / \mathrm{l})$ on cell viability were 28.3 and $24.3 \%$, respectively. When the incubation time was prolonged to $48 \mathrm{~h}$, the inhibitory rates increased to 48.1 and $37.8 \%$, and reached 53.6 and $55.9 \%$, respectively, after $72 \mathrm{~h}$ of treatment. At the lower dose of CrTX $(2 \mu \mathrm{mol} / \mathrm{l})$ and Iressa $(5 \mu \mathrm{mol} / \mathrm{l})$, the inhibitory ratios were only 32.8 and $41.3 \%$ with $72 \mathrm{~h}$ of treatment, respectively (Fig. 1A and B). With a combination of various doses of Iressa and a constant dose of CrTX, or of various doses of CrTX with a constant dose of Iressa, the inhibitory rates on SK-MES-1 cells increased in comparison with the same doses used alone (Fig. 1C and D). The Q score was 0.85-1.15 suggesting there was an additive effect when CrTX was combined with Iressa. Based on the effectiveness on inhibiting viability of SK-MES-1 cells, the concentrations used in subsequent experiments were $1 \mu \mathrm{mol} / \mathrm{l} \mathrm{CrTX}$ with $5 \mu \mathrm{mol} / 1$ Iressa.

The cell colony formation assay also showed that CrTX and Iressa inhibited the colony formation of SK-MES-1 cells in a dose-dependent manner (Fig. 2A and B), and the inhibitory effects were significantly enhanced when they were combined (Fig. 2C and D).

Effects of CrTX on the cell cycle and apoptosis. To understand the mechanisms of CrTX on cell growth inhibition, FCM was used to analyze apoptosis and cell cycle arrest. After treatment for $24 \mathrm{~h}$, the apoptosis rates of SK-MES-1 cells in the control group, the SP600125 with CrTX group, the Iressa group, the CrTX group, and the CrTX with Iressa group were $0.89 \pm 0.06$, $1.03 \pm 0.04,10.7 \pm 1.1,11.8 \pm 1.7$ and $19.6 \pm 2.8 \%$, respectively. The increase in apoptosis in the SP600125 with CrTX group was not statistically significant from the control group $(\mathrm{P}>0.05)$, whereas the apoptosis rate in the CrTX, Iressa and combination-treatment groups increased significantly in comparison to controls $(\mathrm{P}<0.05, \mathrm{n}=3)$ (Fig. 3A and C). SP600125 protected SK-MES-1 cell from apoptosis indicating that the p-JNK signal transduction pathway may play an important role in the activity of CrTX.

Additionally, from the results of the cell cycle analysis, we found that CrTX significantly increased the number of 

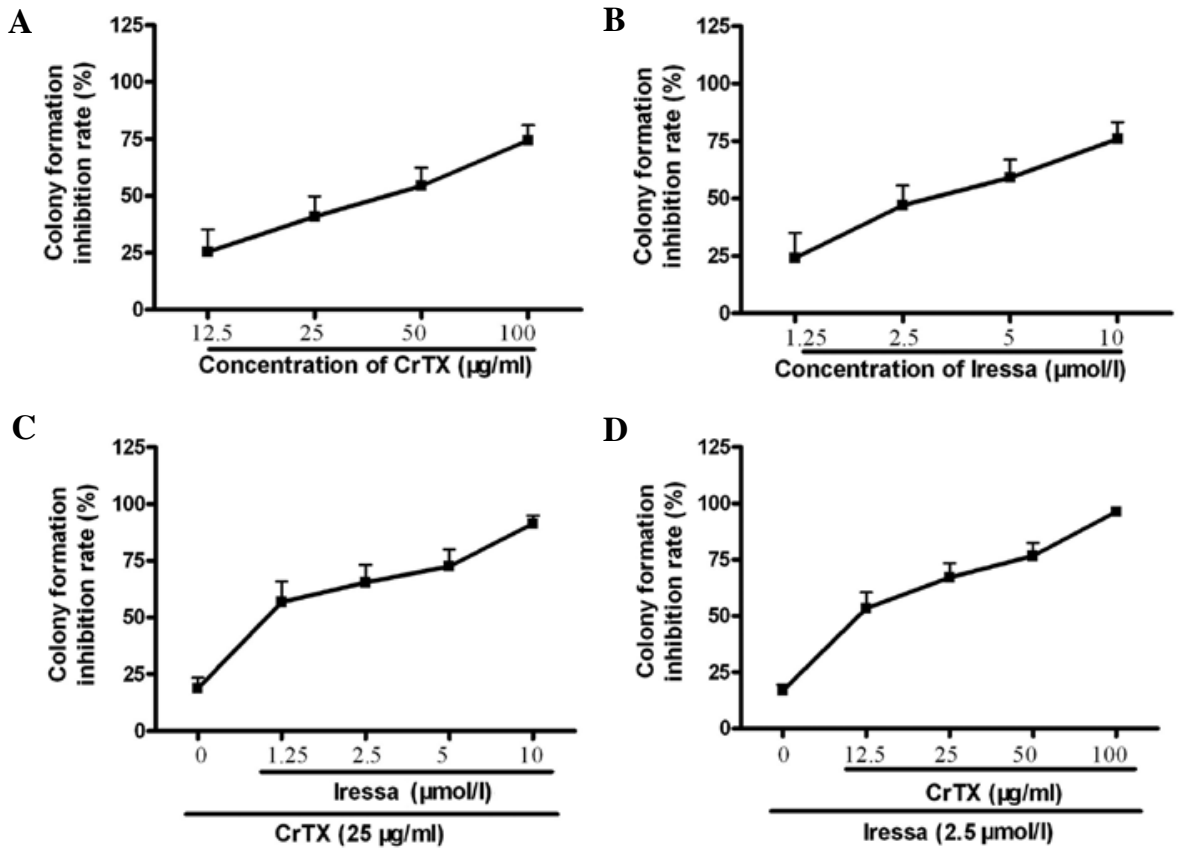

Figure 2. Effects of CrTX and Iressa on colony formation of SK-MES-1 cells. Cell colony formation was analyzed $72 \mathrm{~h}$ after drug treatment. Fresh RPMI-1640 medium replaced the medium with drugs and the cells were incubated for 12 days. After that, cells were fixed with methanol and stained with Giemsa. The colonies including $>50$ cells were calculated. (A and B) Colony formation under the effect of CrTX and Iressa individually. (C and D) Colony formation rate with the combination of CrTX and Iressa; $n=3$. Mean \pm SD.

A

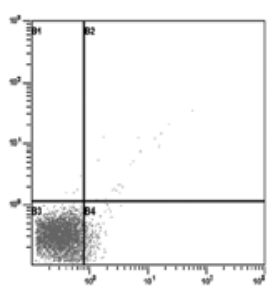

Cont

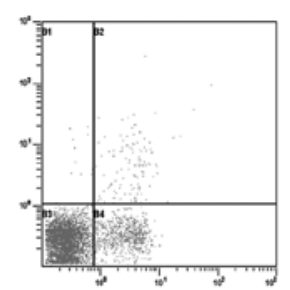

$\mathrm{CrTX}+\mathrm{SP} 600125$

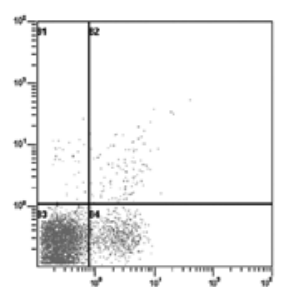

CrTX

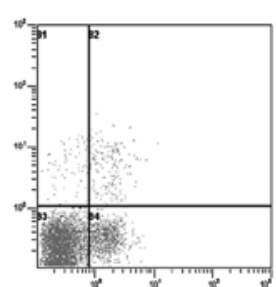

Iressa

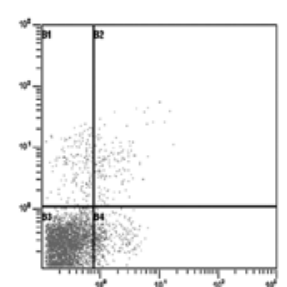

CrTX + Iressa
B

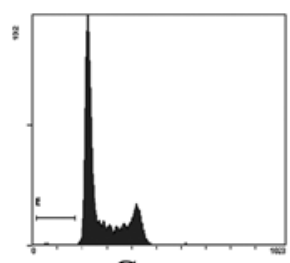

Cont

C

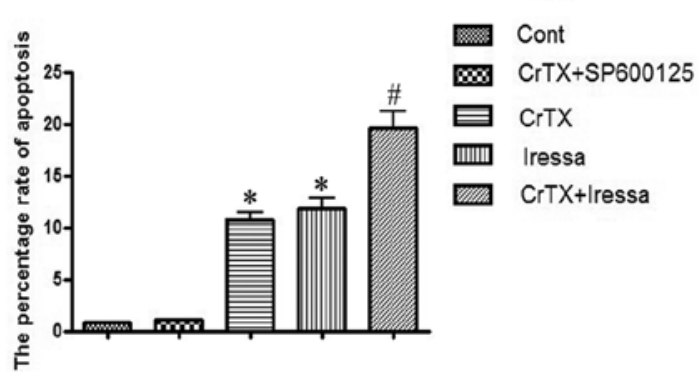

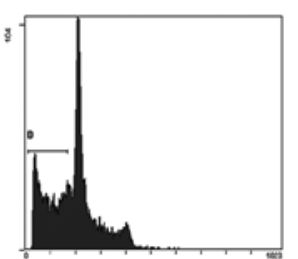

Iressa

D

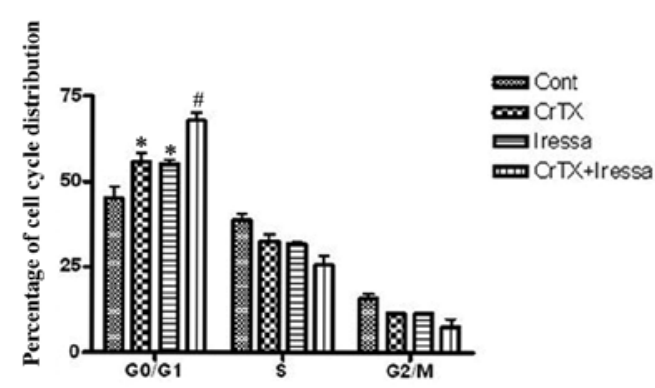

Figure 3. Effects of CrTX on apoptosis and cell cycle of SK-MES-1 cells. (A) Cells were harvested after treatment for $24 \mathrm{~h}$, washed twice with pre-chilled PBS, and resuspended in $500 \mu \mathrm{l}$ binding buffer to a final cell concentration of $1-5 \times 10^{5}$ cells/ml. They were incubated in the dark with $5 \mu 1$ Annexin-V and $5 \mu 1$ PI solution of $20 \mu \mathrm{g} / \mathrm{ml}$ for $30 \mathrm{~min}$. Subsequently, the suspension was analyzed by FCM. (B) After being treated for $24 \mathrm{~h}$, cells were harvested using $0.25 \%$ trypsin, and $10^{6}$ cells per sample were aliquoted for analysis. Cells were centrifuged at 5,000 x g at $4^{\circ} \mathrm{C}$ for $5 \mathrm{~min}$ and washed in cooled PBS, fixed with pre-cooled $70 \%$ ethanol for $24 \mathrm{~h}$, and treated with $200 \mu \mathrm{l} \mathrm{RNase}$ A ( $1 \mathrm{~g} / \mathrm{l})$ for $30 \mathrm{~min}$. Propidium iodide (PI) was added to a final concentration of $20 \mu \mathrm{g} / \mathrm{ml}$ for $30 \mathrm{~min}$ in the dark. Finally, the cell cycle was analyzed with FCM. (C and D) Statistical analysis of A and B, respecively. ${ }^{\mathrm{P}}<0.05,{ }^{\#} \mathrm{P}<0.01 \mathrm{vs}$. controls; $\mathrm{n}=3$. Mean $\pm \mathrm{SD}$. 
A

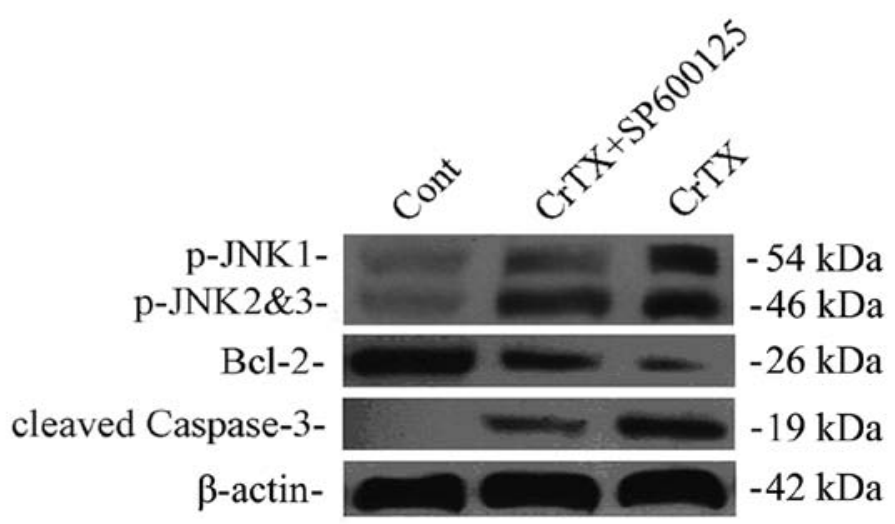

B
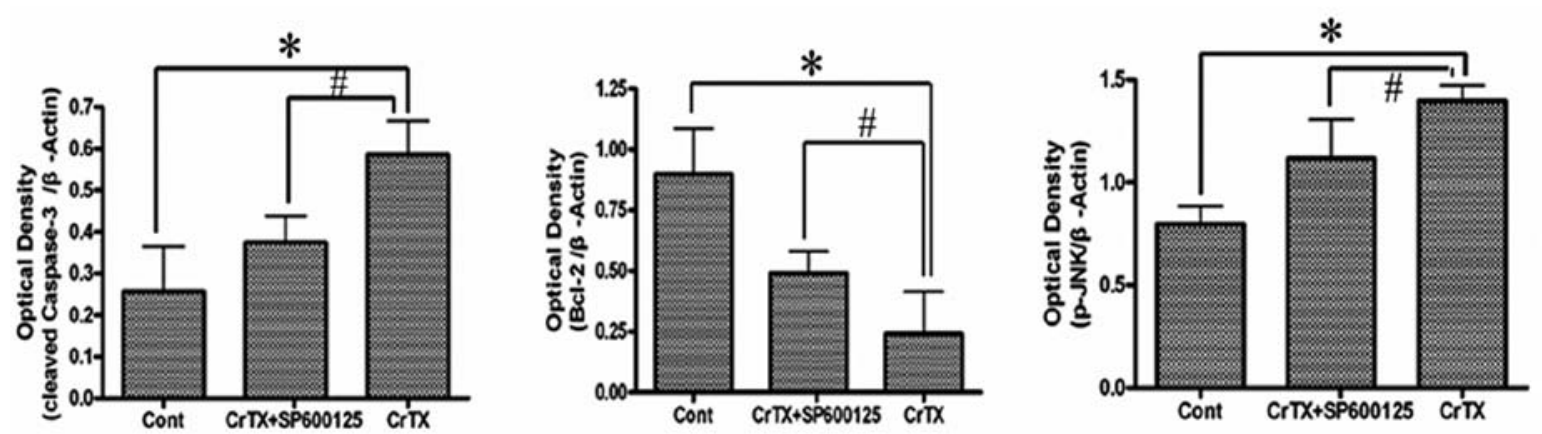

Figure 4. CrTX activates p-JNK, cleaves caspase-3 and reduces Bcl-2 protein in SK-MES-1 cells. Cells were treated with $25 \mu \mathrm{g} / \mathrm{ml} \mathrm{CrTX}$ or $10 \mu \mathrm{mol} / 1$ SP600125 with $25 \mu \mathrm{g} / \mathrm{ml}$ CrTX for $24 \mathrm{~h}$. (A) Cell lysates were collected for western blot analysis of p-JNK, caspase-3, and Bcl-2, and $\beta$-actin was used as a loading control. (B) Protein levels of p-JNK, cleaved caspase-3, Bcl-2 and $\beta$-actin were analyzed. Optical densities of respective protein band were analyzed with Sigma Scan Pro 5 and normalized with loading control. ${ }^{*} \mathrm{P}<0.01$ vs. controls; ${ }^{\text {}} \mathrm{P}<0.01$ vs. CrTX, $\mathrm{n}=3$. Mean $\pm \mathrm{SD}$.

SK-MES-1 cells in the G1 phase compared to the control group (Fig. 3B and D).

CrTX increases active caspase-3 and p-JNK but downregulates Bcl-2. SK-MES-1 cells were treated with $1 \mu \mathrm{mol} / \mathrm{l} \mathrm{CrTX}$ for $24 \mathrm{~h}$ and harvested for western blot analysis of pro-apoptotic proteins. CrTX significantly upregulated cleaved caspase-3 and p-JNK protein but downregulated Bcl-2 protein in SK-MES-1 cells. Pretreatment of SK-MES-1 with SP600125 could effectively inhibit the activation of pro-apoptotic proteins induced by CrTX (Fig. 4).

Antitumor effects of CrTX and/or Iressa in vivo. We evaluated the effects of CrTX, Iressa and CrTX combined with Iressa treatment on the growth of SK-MES-1 cells injected subcutaneously into athymic nude mice. The results showed that treatment with either CrTX or Iressa caused a decrease in tumor size compared to control mice, while treatment of CrTX combined with Iressa induced a significantly greater reduction in tumor weight. The tumor inhibitory rate increased to $35.92 \%$ with the drug combination from a $<23 \%$ maximum with single drug therapy (Fig. 5).

The capillaries in the tumor were analyzed by TEM. In the control group, the capillaries in the interstitial substance of the tumor were plentiful, the shape of the endothelial cells was normal, and the growth of the basal membrane was unabridged. In the experimental group, there were only a few of capillaries. The endothelial cells were engorged and some had shrunk. Apoptotic cells were observed in the tumor. In
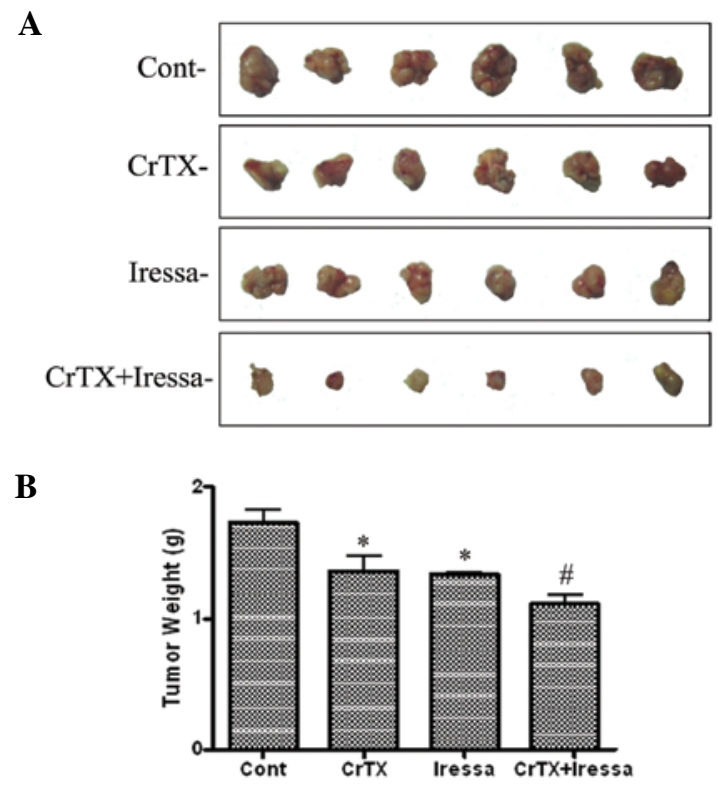

Figure 5. CrTX inhibits the tumor growth. Balb/c nude mice were injected with $10^{7}$ cells $/ \mathrm{ml}$ suspended in $0.2 \mathrm{ml}$ PBS into the left axillary space tissue. Treatments with drugs were initiated 11 days after xenotransplantation and the tumor reached about 5-6 mm in diameter. At the end of 30 days treatment, the mice were sacrificed, and the tumor xenografts were taken out photographed and weighed. ${ }^{*} \mathrm{P}<0.05,{ }^{\text {" }} \mathrm{P}<0.01$ vs. controls, $\mathrm{n}=6$. Mean $\pm \mathrm{SD}$.

the combined treatment group, the appearance of the endothelial cells was much more pronounced. The vessel wall basal 

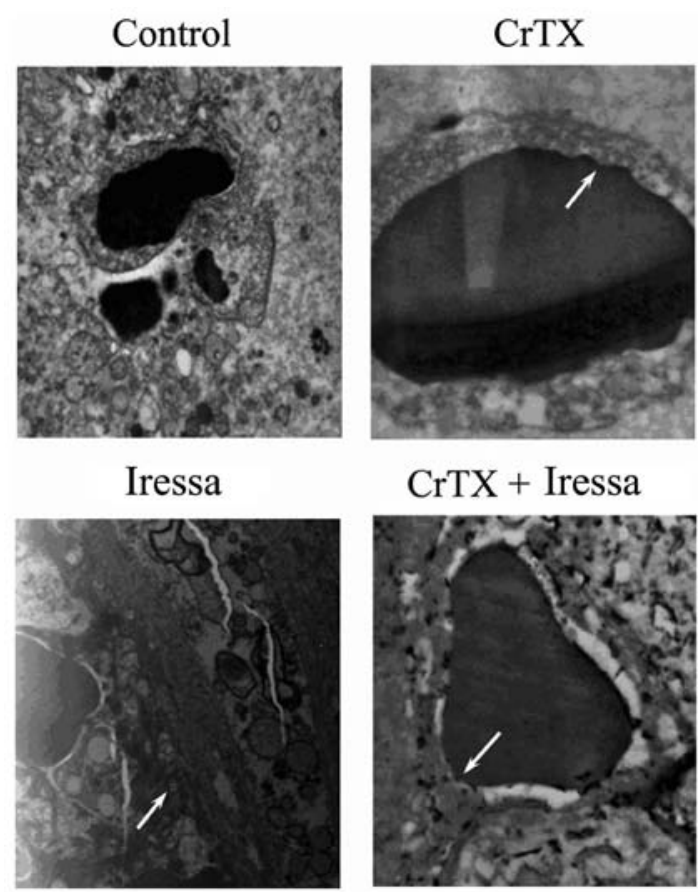

Figure 6. Effects of CrTX on capillaries in tumor tissues. Balb/C nude mice were injected with $10^{7}$ cells $/ \mathrm{ml}$ suspended in $0.2 \mathrm{ml}$ PBS into the left axillary space tissue. Treatments with drugs were initiated 11 days after xenotransplantation and the tumor reached about 5-6 $\mathrm{mm}$ in diameter. At the end of 30 days treatment, the mice were sacrificed, and the tumor xenografts were excised, sectioned and analyzed with transmission electron microscopy.

membrane was ruptured, thinned, and the lumen was narrow; additionally there was electron-dense material in the vascular endothelial cells (Fig. 6).

\section{Discussion}

CrTX is a potent antitumor agent, which has cytotoxic activity against a variety of human tumor cell lines in vitro $(6,7,15)$. CrTX also exerts an anti-inflammatory/analgesic activity seemingly through the lipoxygenase pathway without negatively impacting its anticancer activity. For both functions, CrTX requires the PLA2 activity of subunit B and the ability of the complex to dissociate into its subunits $(9,16)$. Antitumor inhibition in vivo of $83 \%$ has been demonstrated against Lewis lung carcinoma (17) and MX-1 human mammary carcinoma (69\% growth inhibition). A lower activity (44\% growth inhibition) was observed with HL-60 leukemia cells, suggesting that CrTX has certain specificity toward solid tumors.

CrTX-induced cytotoxic effects appear to be highly selective toward cell lines expressing an upregulated density of EGFRs (9), though CrTX appeared to unexpectedly promote EGFR phosphorylation. Enhanced EGFR activity in cancer cells and tumors is associated with increased growth, survival and angiogenesis of tumors (18). The human CML line K562 which has endogenous tyrosine kinase activity and is resistant to imatinib was also quite sensitive to CrTX (7). In this study, the antitumor effects of CrTX against SK-MES-1 cells, possessing resistance to EGFR tyrosine kinase inhibitors, was dose- and time-dependent. When CrTX was combined with Iressa, the antitumor effect of Iressa against this tyrosine kinase resistant cell line was strengthened, which suggests an additive effect of the two drugs. In vivo, CrTX and Iressa both had antitumor effects in mice with tumor xenografts; but the inhibitory rate with the combined treatment was increased by $50 \%$. These data suggest that CrTX stimulation of EGFR phosphorylation is a cellular response to the induction of apoptosis and that the co-utilization of a tyrosine kinase inhibitor blocks this rescue pathway. It should be noted that the animal treatment protocol for CrTX therapy was not optimized through the induction of tolerance (19), but Iressa served to sensitize the tumors permitting low and infrequent dosing of CrTX to be effective.

There is a close and complex relationship between apoptosis of tumor cells and cell cycle arrest. Although they complement each other in inhibiting tumor progression, the effects of CrTX on inducing apoptosis of tumor cells and blocking the G1 phase are achieved through different intracellular pathways. FCM showed that CrTX itself significantly increased the rate of apoptosis of SK-MES-1 cells particularly in the G1 phase indicating that the antitumor effects of CrTX were closely related to induction of apoptosis and to cell cycle arrest.

Many researchers have paid more attention to the signaling pathway mediated by $\mathrm{p}-\mathrm{JNK}$, one of the main signal transduction systems regulating apoptosis $(20,21)$. Cells transmit extracellular signals to the nucleus through this pathway (22). When the pathway is activated by ultraviolet radiation, nerve growth factor, satratoxin, or antitumor drugs, JNK is phosphorylated. Phosphorylated JNK plays an important role in apoptosis and cell cycle arrest (23-25). As a central apoptotic effector, caspase-3 plays a key role in promoting apoptosis (26). When $\mathrm{p} 17$, the active form of caspase-3, is detected, it indicates that caspase- 3 proenzyme is activated and ready to execute its apoptotic function.

In the present study, the expression of p-JNK and p17 increased during the process of CrTX-induced apoptosis of SK-MES-1 cells. The use of SP600125 confirmed the role of the p-JNK signaling pathway. The activation of p-JNK probably mediated the activation of caspase- 3 . JNK protein is normally located in the cytoplasm, and when it is activated, it aggregates in the nucleus as observed herein. Consistent with previous data, the activation of caspase- 3 is an important component of the CrTX mechanism $(7,15)$. The expression of active Bcl-2 was downregulated when the SK-MES-1 cells were treated with CrTX. All of the above are indicative of the induction of apoptosis.

Most antitumor drugs exhibit severe host toxicity due to their poor selectivity toward cancer cells. Iressa, an anti-EGFR tyrosine kinase inhibitor, is widely used clinically in Asia, and its therapeutic effect has been confirmed in a specific cohort of lung cancer subjects. However, it is expensive and its efficacy is limited and is compounded by primary or secondary drug resistance which develops with extended treatment periods. When combined with Iressa, CrTX can significantly increase its tumor suppressive activity or reduce the required dose of Iressa suggesting that CrTX appears to be a useful conjunctive therapy for lung cancer treatment. The present study aids in the understanding of the mechanism of CrTX-induced apoptosis in SK-MES-1 cells, and provides new insight into antitumor combinations for lung cancer therapy. 


\section{Acknowledgements}

This study was funded by the research project of the Jiangsu Province Department of Health (no. 30307001402) and Jiangsu Province's Key Provincial Talents Program (RC2011112).

\section{References}

1. Centers for Disease Control and Prevention (CDC): 2008-2009 Lung Cancer Fact Sheet. CDC, Atlanta, 2009.

2. Petty RD, Nicolson MC, Kerr KM, Collie-Duguid E and Murray GI: Gene expression profiling in non-small cell lung cancer: from molecular mechanisms to clinical application. Clin Cancer Res 10: 3237-3248, 2004

3. Lynch TJ, Bell DW, Sordella R, Gurubhagavatula S, Okimoto RA, et al: Activating mutations in the epidermal growth factor receptor underlying responsiveness of non-small-cell lung cancer to gefitinib. N Engl J Med 350: 2129-2139, 2004

4. Faure G, Harvey AL, Thomson E, Saliou B, Radvanyi F and Bon C: Comparison of crotoxin isoforms reveals that stability of the complex plays a major role in its pharmacological action. Eur J Biochem 214: 491-496, 1993.

5. Aird SD, Kaiser II, Lewis RV and Kruggel WG: A complete amino acid sequence for the basic subunit of crotoxin. Arch Biochem Biophys 249: 296-300, 1986.

6. Rudd CL, Viskatis LJ, Vidal JC and Etcheverry MA: In vitro comparison of cytotoxic effects of crotoxin in three human tumor cell lines and a normal human keratinocyte cell line. Invest New Drugs 12: 183-184, 1994

7. Yan CH, Liang ZQ, Gu ZL, et al: Contributions of autophagic and apoptotic mechanisms to CrTX-induced death of K562 cells. Toxicon 47: 521-530, 2006

8. Penzo D, Petronilli V, Angelin A, et al: Arachidonic acid released by phospholipase $\mathrm{A}(2)$ activation triggers $\mathrm{Ca}(2+)$-dependent apoptosis through the mitochondrial pathway. J Biol Chem 279: 25219-25225, 2004

9. Donato NJ, Martin CA, Perez M, Newman RA, Vidal JC and Etcheverry MA: Regulation of epidermal growth factor receptor activity by crotoxin, a snake venom phospholipase A2 toxin. Biochem Pharmacol 51: 1535-1543, 1996.

10. Ulukaya E, Ozdikicioglu F, Oral, et al: The MTT assay yields a relatively lower result of growth inhibition than the ATP assay depending on the chemotherapeutic drugs tested. Toxicol In Vitro 22: 232-239, 2008.

11. Ram Z, Samid D, Walbridge S, et al: Growth inhibition of tumor maturation and experimental brain tumors in rats treated with phenylacetate. Cancer Res 54: 2923-2929, 1994.
12. Sharrow SO. Overview of flow cytometry. Curr Protoc Immunol Chapter 5: 5.1.1-5.1.8, 2002.

13. Kapanen A, Ilvesaro J, Danilov A, Ryhanen J, Lehenkar P and Tuukkanen J: Behaviour of nitinol in osteoblast-like ROS-17 cell cultures. Biomaterials 23: 645-650, 2002.

14. Kim H, Liu X, Kobayashi T, Conner H, Kohyama T, Wen FQ, Fang Q, Abe S, Bitterman P and Rennard SI: Reversible cigarette smoke extract-induced DNA damage in human lung fibroblasts. Am J Respir Cell Mol Biol 31: 483-490, 2004.

15. Yan $\mathrm{CH}$, Yang YP, Qin ZH, Gu ZL, Paul R and Liang ZQ: Autophagy is involved in cytotoxic effects of crotoxin in MCF-7 cells. Acta Pharmacol Sin 27: 1297-1302, 2007.

16. Corin RE, Viskatis LJ, Vidal JC and Etcheverry MA: Cytotoxicity of crotoxin on murine erythroleukemia cells in vitro. Invest New Drugs 11: 11-15, 1993.

17. Newman RA, Vidal JC, Viskatis LJ, Johnson $\mathbf{J}$ and Etcheverry MA: VRCTC-310-a novel compound of purified animal toxins separates antitumor efficacy from neurotoxicity. Invest New Drugs 11: 151-159, 1993.

18. Chadalapaka G, Jutooru I, Burghardt R and Safe S: Drugs that target specificity proteins downregulate epidermal growth factor receptor in bladder cancer cells. Mol Cancer Res 8: 739-750, 2010.

19. Okamoto M, Viskatis LJ, de la Roza G and Vidal JC: Induction of tolerance to crotoxin in mice. J Pharmacol Exp Ther 265: 41-46, 1993.

20. Yang X, Khosravi FR, Chang HY, et al: Daxx, a novel Fas2 binding protein thatactivates JNK and apoptosis. Cell 89: 1067-1076, 1997.

21. Chen YR and Tan TH: The c-Jun N-terminal kinase pathway and apoptotic signaling (Review). Int J Oncol 16: 651-662, 2000.

22. Ichijo H: From receptor to stress-activated MAP kinases. Oncogene 18: 6087-6093, 1999.

23. Yang GH, Jarvis BB, Chung YJ and Pestka JJ: Apoptosis induction by the satratoxins and other trichothecene mycotoxins: relationship to ERK, p38 MAPK, and SAPK/JNK activation. Toxicol Appl Pharmacol 164: 149-160, 2000.

24. Xia Z, Dickens M, Raingeaud J, Davis RJ and Greenberg ME: Opposing effects of ERK and JNK-p38 MAP kinases on apoptosis. Science 270: 1326-1331, 1995.

25. Davis RJ: Signal transduction by the JNK group of MAP kinases. Cell 103: 239-252, 2000.

26. Kim KW, Kim BJ, Chung CW, et al: Caspase cleavage product lacking amino-terminus of Ikappa Balpha Sensitizes resistant cells to TNF-alpha and TRALL induced apoptosis. J Cell Biochem 85: 334-345, 2002. 